\title{
The long-term effects and detection ranges of passive integrated transponders in white-clawed crayfish Austropotamobius pallipes
}

\author{
Jen Nightingale ${ }^{1,2, *}$, Paul Stebbing ${ }^{3}$, Nick Taylor ${ }^{3}$, Gráinne McCabe $^{2}$ and Gareth Jones ${ }^{1}$ \\ ${ }^{1}$ University of Bristol. Biological Sciences, Life Sciences Building, 24 Tyndall Avenue, Bristol BS8 1TQ, UK \\ ${ }^{2}$ Bristol Zoological Society, Bristol Zoo Gardens, Clifton, Bristol BS8 3HA, UK \\ ${ }^{3}$ Centre for Fisheries, Environment and Aquaculture Science, Barrack Rd, Weymouth DT4 8UB, UK
}

\begin{abstract}
Individual identification of the endangered white-clawed crayfish (Austropotamobius pallipes) can provide valuable information when assessing long-term survival of animals released into the wild; currently the most effective method is the use of passive integrated transponders (PIT) tags. A 360 days ex situ experiment was undertaken on 20-month, captive-born A. pallipes of carapace length (CL): $22-31 \mathrm{~mm}$, to assess growth and survival after PIT-tagging. Thirty crayfish, matched for sex and size, were PIT-tagged, with 30 untagged crayfish as a control. All crayfish survived for the first 60-day post-tagging, indicating that there was no short-term survival effect of the procedure, in controlled conditions. There was no significant difference in survival or growth over the year between tagged and untagged crayfish, indicating that $A$. pallipes $(\geq 22 \mathrm{~mm}$ CL) can be PIT-tagged safely. A second ex situ experiment investigated the detection range of adult, wild-caught, PIT-tagged A. pallipes. Eighteen A. pallipes were tagged with either $8 \mathrm{~mm}$ or $12 \mathrm{~mm}$ tags and added to different treatments (bare tank, tank with substrate, brick refuge, pipe refuge, pipe refuge plus slate), and the distance to detection was measured. Throughout all treatments the A. pallipes tagged with $12 \mathrm{~mm}$ PIT tags were detected significantly further away $(35.6 \pm 3.8 \mathrm{~mm})$ than the $8 \mathrm{~mm}$ PITtagged crayfish.
\end{abstract}

Keywords: white-clawed crayfish / PIT-tagging / detection / conservation

Résumé - Les effets à long terme et les distances de détection des transpondeurs passifs intégrés dans les écrevisses à pattes blanches Austropotamobius pallipes. L'identification individuelle des écrevisses à pattes blanches (Austropotamobius pallipes) menacées d'extinction peut fournir des informations précieuses pour évaluer la survie à long terme des animaux relâchés dans la nature; actuellement, la méthode la plus efficace est l'utilisation de transpondeurs intégrés passifs (PIT). Une expérience ex situ de 360 jours a été entreprise sur des $A$. pallipes de longueur de carapace (CL) de 20 à $31 \mathrm{~mm}$, âgées de 20 mois nées en captivité, afin d'évaluer la croissance et la survie après marquage PIT. Trente écrevisses, assorties pour le sexe et la taille, étaient marquées PIT, avec 30 écrevisses non marquées comme témoin. Toutes les écrevisses ont survécu pendant les 60 premiers jours après le marquage, ce qui indique qu'il n'y avait aucun effet de l'intervention sur la survie à court terme, dans des conditions contrôlées. Il n'y a pas eu de différence significative dans la survie ou la croissance au cours de l'année entre les écrevisses marquées et les écrevisses non marquées, ce qui indique qu' $A$. pallipes $(\geq 22 \mathrm{~mm} C L)$ peut être marquée PIT en toute sécurité. Une deuxième expérience ex situ a examiné la plage de détection des $A$. pallipes adultes capturées à l'état sauvage et marquées PIT. Dix-huit $A$. pallipes ont été marquées avec des marques de $8 \mathrm{~mm}$ ou de $12 \mathrm{~mm}$ et ajoutées à différents traitements (réservoir nu, réservoir avec substrat, refuge en brique, refuge de tuyaux, refuge de tuyaux et ardoise), et la distance de détection a été mesurée. Au cours de tous les traitements, les A. pallipes marquées avec des marques PIT de $12 \mathrm{~mm}$ ont été détectées significativement plus loin $(35,6 \mathrm{~mm} \mathrm{SD}=3,8)$ que les écrevisses marquées PIT de $8 \mathrm{~mm}$.

Mots-clés : écrevisse à pattes blanches / marquage PIT / détection / conservation

\footnotetext{
*Corresponding author:

jnightingale@bristolzoologicalsociety.org.uk
} 


\section{Introduction}

The white-clawed crayfish Austropotamobius pallipes, (Lereboullet, 1858), is globally Endangered throughout its range (Füreder et al., 2010). One of the recognised conservation techniques is to establish ark sites (safe refuges) into which wild populations can be translocated, or captiveborn animals introduced (Souty-Grosset and Reynolds, 2009; Nightingale et al., 2017). Evaluation of the long-term success of these ark sites and the levels of recruitment can be greatly assisted by permanent marking and subsequent monitoring of the crayfish being released. If released crayfish individuals can be identified and tracked over an extended time period, within an ark site, this will provide valuable information on the status, long-term viability, and health of these populations.

The standard marking techniques for tracking crayfish have historically included cauterization, hole-punching, marking with correction fluid or oil-based pens/paints and radio-tracking (Abrahamssons, 1965; Guan, 1997; Robinson et al., 2000; Haddaway et al., 2010; Ramalho et al., 2010; Louca et al., 2014). However, none of these methods provides a permanent method of marking that is retained during moulting and some methods, such as cauterization, have been shown to reduce growth rates (Guan, 1997).

There are several options for permanent marking of crayfish. Visible implant elastomer (VIE) is a liquid elastomer that is injected under the skin, allowing identification of a limited number of individuals or groups by colour combinations or implant location. Visible implant alpha tags (VI Alpha) are small, fluorescent tags with an alphanumeric code; both VIE and VI Alpha are designed to remain visible after they have been implanted within the animal (Gotteland, 2013). Both methods have limitations in terms of unique identification, retention rate, long-term readability and, because the tagged animals cannot be detected remotely, they have to be recaptured to be identified (Buřič et al., 2008; Haddaway et al., 2010). Coded micro-wire tags (CWT) are widely used in the fisheries industry. They are very small $(1.1 \mathrm{~mm} \times 0.25$ $\mathrm{mm}$ ), and therefore can be implanted without survival being compromised. The tags can be detected using hand-held readers; however, individual identification of live animals is difficult because the tag usually needs to be removed to be read (McMahan et al., 2012). One of the most successful methods of permanent tagging, with easy individual identification, is the use of passive integrated transponders (PIT) tags.

PIT tags are electronic chips, encased within glass, ranging in size from approximately $7-32 \mathrm{~mm}$ in length. They remain passive; i.e., dormant, until they are activated by a reader, which emits a close-range electromagnetic field, causing the PIT tag to transmit its unique code. PIT-tagging provides a permanent method to uniquely identify animals (Gibbons and Andrews, 2004). The use of PIT tags for marking animals began in the $1980 \mathrm{~s}$, when it was trialled with salmonids in the fisheries industry (Prentice and Park, 1983). With the development of PIT tag readers with extendable antenna, the tags can be read remotely, hence allowing animals to be identified in situ without having to be captured or seen. This can potentially provide a very useful tool for monitoring populations of species long-term and validating survival rates when captive-born animals are released into the wild, without the need to physically trap or handle the animals to identify individuals.

The use of PIT tags on fish species is well documented (Prentice and Park, 1983; Roussel et al., 2004). In recent years, this technique has been used on crayfish species and there have been several in situ and ex situ studies published. Field experiments include studies on A. pallipes (Bubb et al., 2008; Louca et al., 2014; Stead et al., 2015), slender crayfish Orconectes compressus, (Black et al., 2010), giant Tasmanian crayfish Astacopsis gouldi (Shepherd et al., 2011) and signal crayfish Pascifastacus leniusclus (Stead et al., 2015). Laboratory experiments include studies on $P$. leniusclus (Wiles and Guan, 1993; Bubb et al., 2002), spiny-cheek crayfish Orconectes limosus (Buřič et al., 2008), O. compressus (Black et al., 2010), and woodland crayfish Orconectes hylas (Westhoff and Sievert, 2013). High survival rates and good growth rates have been reported in most cases, when tagging crayfish $>25 \mathrm{~mm}$ carapace length (CL). However, previous laboratory studies were relatively shortterm, typically less than 60-days in length, with one longer sixmonth study reported (Bubb et al., 2002).

There have been no known published laboratory trials to assess survival and growth of PIT-tagged A. pallipes. There are a few published field studies, which have shown that PIT-tagged $A$. pallipes survived when returned to the wild (Bubb et al., 2010; Louca et al., 2014; Stead et al., 2015). However, in all of these studies, only a proportion of the released tagged crayfish were detected and therefore percentage survival and growth of A. pallipes, post-tagging, could not be confirmed.

PIT tags are available in a range of sizes and there have been several studies looking at the detection range of fish species that have been tagged with different sized PIT tags (Morhardt et al., 2000; Burnett et al., 2013). However, there are no known published studies looking at the difference in detection range of crayfish tagged with different sized PIT tags. Bubb et al. (2002) and Burnett et al. (2013) assessed the specific range at which different sized PIT tags could be detected when placed in a river, but these crayfish were not internally PIT-tagged.

The objectives of the present study were two-fold: (i) to investigate the long-term effects of PIT-tagging on survival and growth of captive-born $A$. pallipes, within the laboratory, and to establish a minimum size at which $A$. pallipes can be safely tagged; and (ii) to investigate the detection range of PITtagged captive-born $A$. pallipes with $8 \mathrm{~mm}$ versus $12 \mathrm{~mm}$ PIT tags, within a variety of laboratory conditions. Both experiments should help to inform the efficacy of using PIT tags for long-term monitoring of $A$. pallipes in situ and the safe minimum size at which $A$. pallipes can be PIT-tagged.

\section{Materials and methods}

\subsection{Investigating the effect of pit-tagging on growth and survival of $A$. pallipes ex situ}

A year-long experiment was conducted in an outdoor, flowthrough, aquaculture facility in Somerset, United Kingdom. Sixty, captive-born, 20-month A. pallipes were used in the experiment: 30 males and 30 females. The juveniles were hatched from 20 wild-caught, ovigerous females (collected 
Table 1. Mean carapace lengths (CL mm) of A. pallipes within the treatment and control groups for each of the replicate tanks (Tank 13).

\begin{tabular}{lccc}
\hline Treatment/control & Tank 1 & Tank 2 & Tank 3 \\
& CL mm & CL mm & CL mm \\
\hline Male tag & $27.4 \pm 4.0$ & $27.5 \pm 4.5$ & $25.6 \pm 3.3$ \\
Male untagged & $28.1 \pm 7.1$ & $27.3 \pm 1.2$ & $26.1 \pm 3.6$ \\
Female tag & $25.6 \pm 1.1$ & $26.1 \pm 2.6$ & $24.8 \pm 2.7$ \\
Female untagged & $24.4 \pm 1.7$ & $25.0 \pm 3.5$ & $24.6 \pm 3.0$ \\
\hline
\end{tabular}

from a local river population within South Gloucestershire, under licence) that were reared for the first year in a nearby indoor, closed-circuit aquaculture facility and then moved to the outdoor aquaculture facility ten-months prior to the experiment commencing.

The crayfish were split into three groups, 20 crayfish in each, with an equal sex ratio and, within each sex, an equal mean CL and weight. Each tank group was then divided into tagged (treatment) and control sub-groups, with equal sex ratio (Tab. 1).

Crayfish in the treatment sub-groups were tagged with Trovan ID100A/1.4, (RFID Systems LTD, East Yorkshire), $8 \mathrm{~mm} \times 1.4 \mathrm{~mm}$ PIT tags and animals in the control group were left untagged. For the tagging procedure, the crayfish were held around the cephalothorax and an incision made, with a sterile $2 \mathrm{~mm}$-gauge, hypodermic needle, through the cuticle and abdominal muscle of the third ventral abdominal segment (i.e., between the second and third set of pleopods). The tag was then injected into the abdominal muscle and the crayfish was scanned with a Trovan LID-575 midrange reader (RFID Systems LTD, East Yorkshire) and the tag code recorded.

Each group of 20 crayfish was then randomly assigned to one of three experiment tanks $\left(0.9 \mathrm{~m}^{2}\right.$ bottom area), on continuous flow-through from a local water reservoir and with an excess of refuges, (engineered bricks and PVC pipes, no substrate). Water temperature was allowed to fluctuate naturally with the incoming water and was recorded hourly with an aquatic TinyTag data logger (Gemini Data Loggers Ltd, West Sussex). Temperature varied seasonally between 5.8 and $22.5^{\circ} \mathrm{C}$, with no more than $2.8^{\circ} \mathrm{C}$ variation over a $24 \mathrm{~h}$ period. Water quality was monitored monthly using a Colombo Testlab water-testing kit (Aquadistri UK Ltd products, Cambridgeshire). Chemical levels remained constant throughout the experiment: ammonia $<0.1 \mathrm{mg} / \mathrm{l}$, nitrite $<0.1 \mathrm{mg} / \mathrm{l}$, nitrate $15 \mathrm{mg} / \mathrm{l}$, phosphate $<0.1 \mathrm{mg} / \mathrm{l}, \mathrm{pH} 8.0$, calcium $35 \mathrm{mg} / \mathrm{l}$, general hardness $12 \mathrm{KH}$, potassium hardness $10 \mathrm{KH}$ and a level of dissolved oxygen $>80 \%$. The photoperiod was natural and therefore fluctuated with season; average values were $12 \mathrm{~h}$ light and $12 \mathrm{~h}$ dark. No supplementary feeding occurred during the experiment; the crayfish foraged on live invertebrates and plant matter, existing within the tanks. This naturally occurring food supply was in constant supply from the incoming water. The experiment ran for 12-months, from the end of January 2016 until beginning of January 2017. At the end of the experiment, all surviving tagged crayfish were X-rayed with a Roentgen 703 machine (C and G Medical) and processed with a Direct Digitizer Regius model 110 (Konica Minolta), to assess the internal position of the PIT tags.
Table 2. Mean carapace lengths (CL mm) of A. pallipes within the two PIT-tagged treatment groups: $8 \mathrm{~mm}$ and $12 \mathrm{~mm}$ tags.

\begin{tabular}{cccc}
\hline \multicolumn{1}{c}{ Treatment } & $\begin{array}{c}\text { Male } \\
\text { CL mm }\end{array}$ & $\begin{array}{c}\text { Female } \\
\text { CL mm }\end{array}$ & $\begin{array}{c}\text { Male: } \\
\text { female ratio }\end{array}$ \\
\hline $8 \mathrm{~mm} \times 1.4 \mathrm{~mm}$ PIT-tag & $34.5 \pm 1.5$ & $35.1 \pm 3.2$ & $5: 4$ \\
$12 \mathrm{~mm} \times 2.1 \mathrm{~mm}$ PIT-tag & $40.9 \pm 3.2$ & $38.9 \pm 1.7$ & $4: 5$ \\
\hline
\end{tabular}

\subsubsection{Data collection and analysis}

The crayfish were counted every 60 days; i.e., on day 1,60 , 120, 180, 240, 300 and 360. On each counting day, crayfish were scanned and biometric data recorded. CL was measured from the anterior edge of the rostrum to the posterior edge of the cephalothorax to the nearest $0.1 \mathrm{~mm}$ using Vernier callipers (Moore and Wright, Sheffield). The crayfish were dried with paper towel and weighed to the nearest $0.1 \mathrm{~g}$ using a digital weighing scale (Smart Weigh SWS600). Missing chelae, a standard measure of aggression, (Figiel and Miller, 1995) and stage in moulting cycle, (i.e. whether inter-moult, pre or post moult), were also recorded. During the breeding season reproductive status was recorded; i.e., if females were in reproductive glair (development of glair glands on the ventral abdomen of the female), egg production or had spermatophores (deposited by males) present.

To determine if there was any difference in the survival of the tagged treatment and the untagged control, data were log transformed and examined by using generalized linear models (function $\mathrm{glm}$, R package lme4, Bates et al., 2015). To determine if there was any difference in growth of the tagged and untagged group, data were examined using linear models (function $l m, \mathrm{R}$ package, Bates et al., 2015). The treatment, control groups and sex were considered as fixed effects, and tank was considered as a random effect. The alpha level was set at $p<0.05$. Only variables that had a significant effect were retained in the model, and the most appropriate model was identified by using the Akaike's Information Criterion corrected for small sample sizes (AICc). Where models were considered equivalent; i.e., $\mathrm{AICc}<2$, the model with the fewest parameters was chosen (Burnham et al., 2011). Statistical analyses were performed using R 3.2.5.

\subsection{Investigating the detection rates of tagged $A$. pallipes ex situ}

Eighteen, wild-caught adult $A$. pallipes crayfish (collected from the River Itchen, Hampshire), which had been maintained in an outdoor aquaculture facility for 9-13 months, were PITtagged one week prior to the experiment commencing, using the technique described in method 2.1 (Tab. 2).

An experimental tank $(2000 \mathrm{~mm} \times 500 \mathrm{~mm} \times 750 \mathrm{~mm})$ was used and water from the crayfish aquaculture system was added to a depth of $650 \mathrm{~mm}$. The tank was set up in one of five different treatments: (i) bare tank; (ii) tank with gravel substrate (to a depth of $20 \mathrm{~mm}$ ); (iii) gravel substrate plus pipe refuge $(50 \mathrm{~mm}$ diameter); (iv) gravel substrate plus brick refuge (50 $\mathrm{mm}$ diameter); (v) gravel substrate plus pipe refuge with slate $(15 \mathrm{~mm}$ thickness $)$ over pipe. The PIT-tagged 


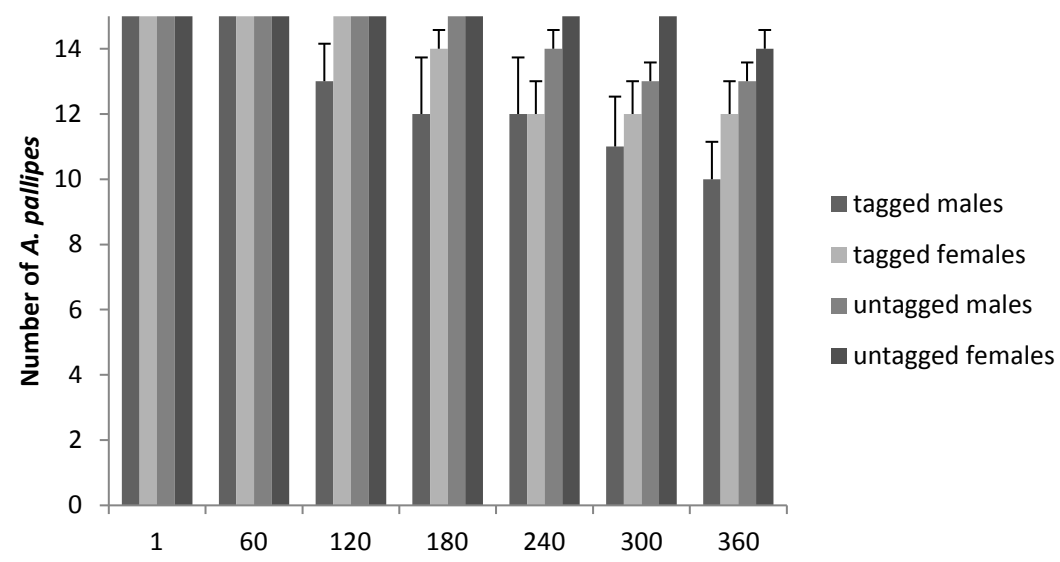

Fig. 1. Survival of PIT-tagged male and female A. pallipes compared with untagged males and females, shown throughout time series from day 1 to 360 of experiment, $n=30$. Error bars represent standard deviations.

crayfish were added, one-by-one, to the experimental tank and the range of detection of each crayfish in each of the different treatments was measured using a single-coil waterproof (IP54 rated) Trovan ANT-610F square antenna attached to a Trovan LID-65 decoder box (RFID Systems LTD, East Yorkshire). The same crayfish was subjected to all five treatments sequentially and then removed and the next crayfish tested. For treatments iii, iv and $\mathrm{v}$, refuges were added and the crayfish was put inside the refuge before the detection range was measured. Both experiments were carried out under Natural England Licence and were ethically approved by the University of Bristol ethics committee and the Bristol Zoological Society Welfare and Research Advisory Board.

\subsubsection{Data collection and analysis}

The antenna was placed in the tank under the surface of the water and moved towards the crayfish until the decoder box produced an audible noise, signifying that the PIT tag had been detected. The distance between the crayfish and the antenna was then measured to an accuracy of $1 \mathrm{~mm}$ using a $300 \mathrm{~mm}$ rule. The process was repeated three times for each crayfish and the mean value calculated.

To determine if there were any differences between the PIT tags of variable size and the distance to detection in the five different treatments, data were examined by using linear models (function $l m$, R package lme4, Bates et al., 2015) with normal distribution. The five different treatments, sex and tag size were considered as fixed effects. Model selection was based on the criteria (as outlined in 2.1.1).

\section{Results}

\subsection{Investigating the effect of pit-tagging on growth and survival of $A$. pallipes ex situ}

\subsubsection{Survival}

All crayfish survived up until day 60 . From day 60 to 360 , several crayfish went missing and were therefore presumed dead, although their bodies/gastroliths were not recovered; the crayfish could not have escaped as the outflows were meshed and the tanks lidded. Eight tagged crayfish died in total, with CLs at the start of the experiment ranging from 22 to $32 \mathrm{~mm}$ : males 22-32 $\mathrm{mm}$ and females $25-27 \mathrm{~mm}$. Two tagged crayfish died prior to each of the May (day 120), July (day 180) and September (day 240) counts and one tagged crayfish died prior to each of the November (day 300) and final January (day 360) count. Five of the eight crayfish (CL: $25-32 \mathrm{~mm}$ ) that died had moulted successfully at least once. The other three crayfish (CL: $22-27 \mathrm{~mm}$ ) died before moulting could be confirmed. From day 180, three untagged crayfish died in total, with starting CL: 22-29 mm. All untagged crayfish had undergone two successful moults prior to death. The two males (CL: $26 \mathrm{~mm}$ and $29 \mathrm{~mm}$ ) died between August (day 180) and November (day 300) and the only untagged female to die (initial $\mathrm{CL}=22 \mathrm{~mm}$ ), was found dead at the end of the experiment, $\mathrm{CL}=33.4 \mathrm{~mm}$. Although only one untagged female died in comparison with 5 tagged males, there were no significant effects of $\operatorname{sex}(P=0.31$, d.f. $=56, z=-1.0)$ or tagging (pooled sex: $P=0.1$, d.f. $=56, z=1.63$ ) on survival rates (Fig. 1).

\subsubsection{Growth}

$\mathrm{CL}$ at the start of the experiment were not significantly different between tanks $(P=0.16$, d.f. $=56, F=1.97)$ or treatments $(P=0.63$, d.f. $=56, F=0.24)$ but males were significantly larger (mean $\pm \mathrm{SD})(27.0 \pm 2.6 \mathrm{~mm})$ than females $(25.0 \pm 2.1 \mathrm{~mm}) ;(P<0.001$ d.f. $=44, F=44.88)$. After adjusting for the differences in starting length for males and females, the model showed that there was no significant effect of treatment $(P=0.61$, d.f. $=48, t=-0.27)$ or tank on final CL $(P=0.48$, d.f. $=46, t=-0.71)$. There was a significant effect of sex; over the course of the experiment, on average the males' CL increased by $8.6 \pm 1.1 \mathrm{~mm}$ ) and the females increased by $7.5 \pm 1.5 \mathrm{~mm})$, showing that the males grow faster than the females $(P<0.001$, d.f. $=46, t=3.41)$, (Fig. 2).

\subsubsection{Moulting events}

All moulting events occurred between the end of March (day 60) and the end of September (day 240). First moults had all occurred between day 60 and day 120. Of the tagged crayfish, $90 \%$ moulted successfully and it was unconfirmed if the three tagged crayfish that died between counts had already moulted because their bodies were not recovered. Males with 


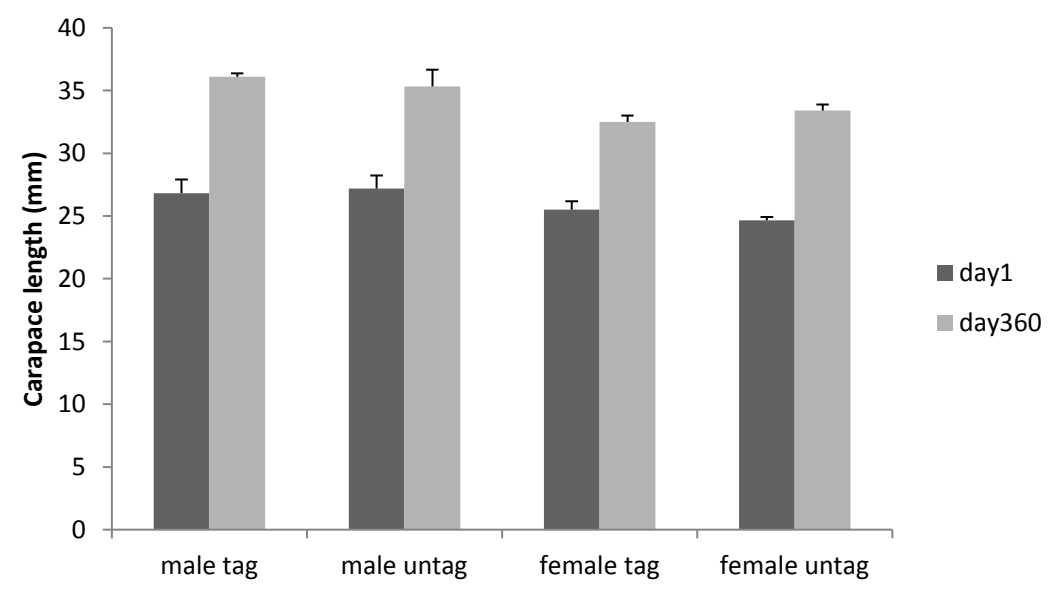

Fig. 2. Carapace length (mm) of PIT-tagged male and female A. pallipes compared with untagged males and females, at the beginning (day 1) and end of the experiment (day 360) $n=30$. Error bars represent standard deviations.

$\mathrm{CL}<29 \mathrm{~mm}$ moulted three times, and males with CL $>29 \mathrm{~mm}$ moulted twice. Females with $\mathrm{CL}<26 \mathrm{~mm}$ moulted three times, and females with CL $>26 \mathrm{~mm}$ moulted twice. There was an inverse relationship between moult increments; i.e., the increase in size of crayfish between moults, and CL and the percentage moult increment decreased as the crayfish grew. Moult increments decreased with an increase in size of crayfish from a maximum of $5.2 \mathrm{~mm} \mathrm{CL}$ increase (18.8\% moult increment) down to a $2 \mathrm{~mm}$ CL increase (5.9\% moult increment). Females on average grew slower than males at all sizes.

The crayfish were X-rayed at the end of the experiment. In $25 \%$ of the crayfish, the PIT-tag had remained within the abdomen, and in $75 \%$ of the crayfish, the PIT-tag had moved into the cephalothorax and was positioned close to the dorsal cuticle, adjacent to the hepatopancreas (Fig. 3).

\subsubsection{Fecundity}

All tagged female $A$. pallipes came into reproductive glair and $80 \%$ of the untagged females came into glair, which was visible at the September count (day 240). At the November count (day 300), three tagged and one untagged female had spermatophores present and one tagged and one untagged female had a single fertile egg attached to their abdomens. Both eggs were still present and viable at the end of the experiment (day 360).

\subsection{Investigating the detection rates of tagged $A$. pallipes ex situ}

There was a significant difference in detection range between crayfish tagged with $8 \mathrm{~mm}$ tags to crayfish tagged with $12 \mathrm{~mm}$ tags in all five treatments $(P<0.001$, d.f $=79, t=9.4)$. Crayfish tagged with $12 \mathrm{~mm}$ tags were detected by the PIT tag antenna on average $35.6 \mathrm{~mm}(\mathrm{SD}=3.8 \mathrm{~mm})$ further away than the crayfish tagged with $8 \mathrm{~mm}$ PIT tags. There was no significant difference in distance detection rates with bare tanks and tanks with a gravel substrate $(P=0.55$, d.f. $=79$, $t=0.59)$. There was a significant difference between detection range of crayfish in a bare/substrate tank versus within bricks
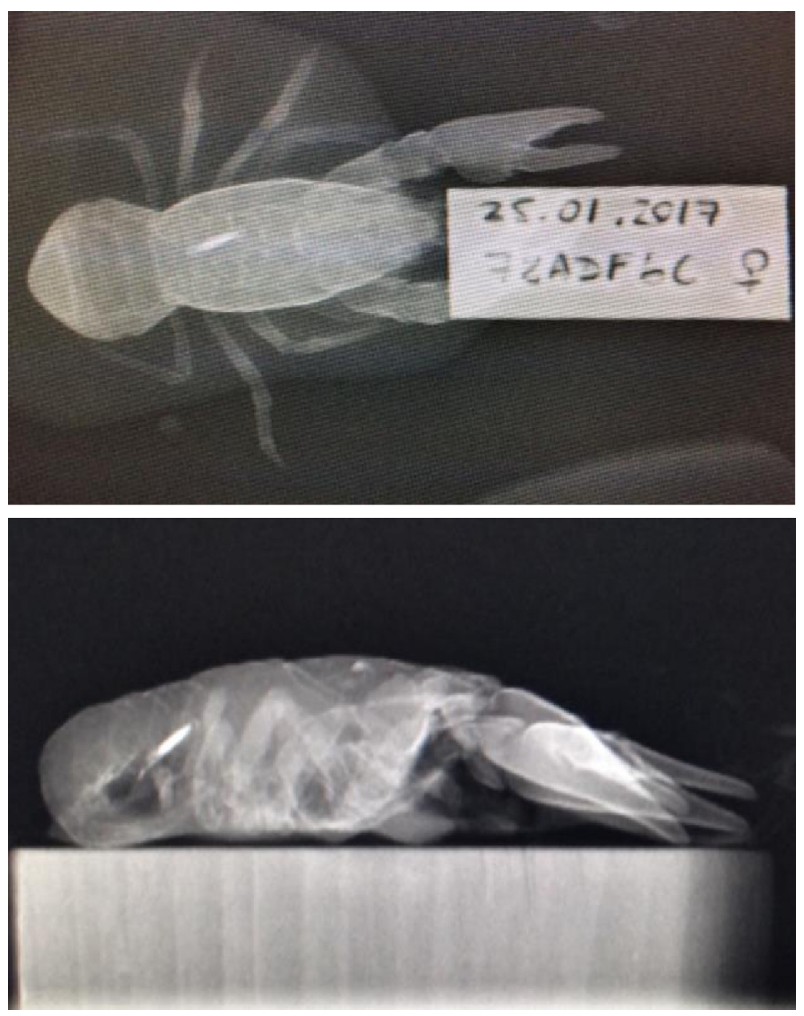

Fig. 3. X-rays of PIT-tagged A. pallipes taken one-year post-tagging.

$(P<0.001$, d.f. $=79, t=-11.90)$, pipe $(P<0.001$, d.f. $=79$, $t=-10.47)$ or pipe plus slate $(P<0.001$, d.f. $=79, t=-10.37)$. There was no significant difference between detection rate of tagged crayfish within bricks versus pipes $(P=0.16$, d.f. $=79$, $t=1.45)$ or bricks versus pipe plus slate $(P=0.13$, d.f. $=79$, $t=1.53)$. There was also no significant difference between pipes versus pipes plus slate $(P=0.92$, d.f. $=79, t=0.10)$ (Fig. 4). There was no significant difference in detection rate between males and females $(P=0.59$, d.f. $=83, t=-0.53)$, or crayfish of different sizes $(P=0.12$, d.f. $=77, t=1.57)$ (Fig. 4$)$. 


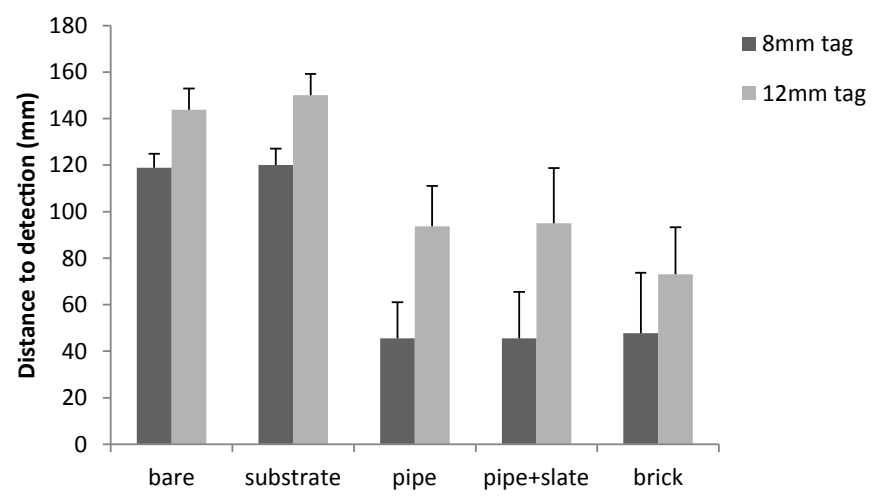

Fig. 4. Comparison of detection ranges of $A$. pallipes tagged with $8 \mathrm{~mm}$ or $12 \mathrm{~mm}$ passive integrated transponders, within five different tank treatments, $n=8$. Error bars represent standard deviations.

\section{Discussion}

The current study found that there was no significant difference in survival, growth or fecundity between $A$. pallipes injected with $8 \mathrm{~mm}$ PIT and the untagged control animals. All of the crayfish survived for at least the first 60 days of the experiment, and there was a $100 \%$ retention rate of PIT tags. This experiment was conducted with a fairly small number of animals due to the endangered status of the species. It would not have been ethical to tag a large number in case survival was significantly compromised by the procedure.

These experimental findings are supported by previous laboratory trials tagging other crayfish species. In a 50-day experiment undertaken by Wiles and Guan (1993), survival and growth of P. leniusculus tagged with $12 \mathrm{~mm}$ tags was not significantly different to untagged crayfish if $\mathrm{CL}>26 \mathrm{~mm}$. Bubb et al., (2008), undertook a 182-day experiment and found that survival and growth of P. leniusculus, CL: $33.7-61.4 \mathrm{~mm}$, tagged with $12 \mathrm{~mm}$ tags, was not significantly different to untagged crayfish, (93.3 and $96.7 \%$ survival rate respectively). In a laboratory experiment with $O$. hylas, Westhoff and Sievert (2013), randomly tagged 96 crayfish CL: $15.3-33.3 \mathrm{~mm},(44$ were untagged as a control). They found that mortality dropped below $20 \%$ if crayfish CL $>23 \mathrm{~mm}$ and $\mathrm{CL}>26 \mathrm{~mm}$ were tagged with $8.5 \mathrm{~mm}$ and $12.5 \mathrm{~mm}$ tags, respectively. However, they also experienced a high mortality of untagged crayfish $(20 \%)$, which may suggest there were underlying husbandry issues that might have masked the results of the experiment.

In a laboratory-based experiment with $P$. leniusculus, Wiles and Guan (1993), used $13 \mathrm{~mm}$ tags and injected the tags either at the base of the fourth pereopod or at the first pleopod ventrally into the cephalothorax, close to the internal organs. They observed unusual behaviour after tag insertion with crayfish stretching out legs and or chelipeds after the procedure and in crayfish $\mathrm{CL}<25 \mathrm{~mm}, 47.6 \%$ died within ten days. They concluded that the PIT tags caused internal organ damage in the smaller crayfish and temporary reduction in leg movement in the some of the larger specimens. In this current experiment, the PIT tags were injected lower down the crayfish, into the muscle of the third segment of the abdomen, to reduce the risk of damaging internal organs whilst the tag was being inserted (Buřič et al., 2008). The difference in tagging procedure may explain why smaller crayfish could be tagged without survival being compromised, and no temporary reduction in crayfish mobility was observed. The X-rays of the tagged A. pallipes taken on day-360 showed that most of the tags had only moved slightly from where they were injected into the abdomen and were positioned either just into the cephalothorax (next to the hepatopancreas) or still just slightly further up the abdomen (Fig. 3).All of the A. pallipes in this study survived the first 60 days indicating that tagging does not cause mortality in the short-term, under controlled conditions, and, up to day 180 , there were only three deaths $(10 \%)$ of PIT-tagged individuals. After day 180, similar numbers of tagged (4) and untagged (3) crayfish died, suggesting that these mortality events were not connected to the tagging event. This is supported by Wiles and Guan (1993), who concluded that crayfish mortalities occurring a few weeks after the tagging procedure could not be attributed to the physical tagging procedure because control animals also died.

Mortality events in the current experiment could be linked to moulting. The crayfish were held at a density equivalent of $5.8 / \mathrm{m}^{2}$ and therefore, during moulting, they could be susceptible to antagonistic encounters from tank-mates. There was no supplementary feeding during the experiment, which might also have had an effect. Bubb et al., (2008) and Wiles and Guan (1993), housed the experimental crayfish individually and therefore removed any potentially negative effects of tank-mates or competition for resources such as food and shelter.

This study is the first known laboratory trial of PIT-tagging A. pallipes. There are several published field studies on PITtagged $A$. pallipes released into rivers, which indicate that a large proportion of tagged crayfish survive at least short-term. These field studies did not investigate survival or growth rates of individual crayfish over time or minimal size of crayfish that could be safely tagged, (Bubb et al., 2008; Louca et al., 2014; Stead et al., 2015). Therefore, the current study is the first to illustrate that growth and survival of both sub-adults and adult A. pallipes is not compromised by the PIT-tagging procedure.

During this experiment, both tagged and untagged crayfish successfully moulted up to three times from spring through to autumn, and growth was not significantly different between tagged and untagged crayfish. Laboratory studies on other crayfish species also found that growth was not affected by PIT-tagging (Wiles and Guan, 1993; Westhoff and Sievert, 2013). Bubb et al., (2006) found that although growth was not significantly different, the tagged crayfish were $10 \%$ smaller than untagged individuals by the end of the experiment; tagged male crayfish were $4.7 \%$ larger than untagged males, whereas untagged females were 3.9\% larger than tagged females.

In this current experiment, the captive-born crayfish were only 2.5 years old at the beginning of the breeding season, and therefore, were potentially too immature to successfully produce large clutches of eggs. This has also been seen in other groups of 2+year captive-born crayfish (pers. obs.); however, it could be that keeping the crayfish with an equal ratio of males at a density of $5.8 / \mathrm{m}^{2}$ caused other males to interrupt mating causing egg loss during egg-laying. The effect of PIT tagging on the reproductive success $A$. pallipes could not be comprehensively established. As all tagged females came into glair, two females produced viable eggs and signs of successful mating were observed it does not appear that breeding activity is impaired. This is supported by Wiles and Guan (1993), who 
tagged ovigerous P. leniusculus, which then carried their eggs full-term.

This study shows that $A$. pallipes with a CL of $22 \mathrm{~mm}$ could be PIT-tagged without survival or growth being compromised. When releasing captive-born crayfish, the individuals will rarely be larger than this size and therefore tagging with largersized PIT tags is not a suitable option as this may well compromise survival. When the detection range of the $8 \mathrm{~mm}$ tagged crayfish was compared with $12 \mathrm{~mm}$ tagged crayfish the average difference in range was marginal $(35.6 \mathrm{~mm})$, which indicates that tagging with $8 \mathrm{~mm}$ tags is a good compromise. Using a single-coil antenna, the $8 \mathrm{~mm}$ tagged crayfish could be detected to a maximum distance of $120 \mathrm{~mm}$ when not within refuges, which was reduced to a maximum distance of $60 \mathrm{~mm}$ when the crayfish was inside a refuge. Despite detection range limitations, it was encouraging to note that even when the crayfish was within a brick refuge, the PIT-tag antenna could still detect the animal. Larger, multiple-coil antennae are available, which can increase the detection range; however, they are heavier and more expensive. In practice, it can be very difficult to reliably detect crayfish remotely in situ, and recapture through trapping is the preferred method. Burnett et al., (2013) compared detection rates and range of detection for tags of sizes 12,23 , and $32 \mathrm{~mm}$. The tags were attached to rocks underwater and the range of detection was an average of 120,202 , and $290 \mathrm{~mm}$, respectively. When tagged fish were tested, detection efficiency significantly increased with size of tag from $55 \%$ for $12 \mathrm{~mm}, 91 \%$ for $23 \mathrm{~mm}$ and $97 \%$ for $32 \mathrm{~mm}$ tags. However, $23 \mathrm{~mm}$ tags are too big for even the largest of $A$. pallipes, which have a maximum CL of up to $55 \mathrm{~mm}$ (Matthews and Reynolds, 1995). The smallest crayfish that were tagged with an $8 \mathrm{~mm}$ tag had a minimum CL of $22 \mathrm{~mm} ; i$. e., the tag was $36 \%$ of the size of the carapace. Working on this principle, if a $23 \mathrm{~mm}$ tag to be used, the crayfish would need to have a CL of $63 \mathrm{~mm}$, minimum.

When captive-born crayfish are released into the wild, this is typically done with yearling animals. The ideal minimum size for release is at a CL of $22 \mathrm{~mm}$ or above to make them less prone to predation and more likely to breed in the year of release. At this size, it also allows them to be safely PIT-tagged prior to release. However, PIT are still relatively expensive ( $€ 1.1 / \mathrm{tag})$; in comparison to other internal markers, such as VIE and CWT, which are considerably cheaper options (a few cents per tag). These other tagging options are suitable for crayfish $<22 \mathrm{~mm}$ CL, (due to their smaller size); however, they have their limitations. Haddaway et al. (2010) tested VIE with $A$. pallipes (CL: $9.5-31.1 \mathrm{~mm}$ ), and found there was an $87.9 \%$ retention rate and a $36.0 \%$ tag migration rate over a 103 -day period. They did not find a significant decrease in survival; however, survival in both the tagged $(64.4 \%)$ and untagged $(60.0 \%)$ groups was fairly low. Gotteland (2013) found no significant difference in survival when using VI Alpha, but experienced $33.0 \%$ mortality during a 60-day trial using VIEs with $A$. pallipes. In an experiment with the American lobster, Homarus americanus (H. Milne Edwards, 1837), McMahan et al., (2012) fitted CWTs and had an average $96 \%$ retention rate, CL: $12-30 \mathrm{~mm}$. Where large groups of crayfish require a group identification system at low cost, VIE could potentially be a solution. However, with this technique, identification of individual live animals would be difficult, tag retention is not $100 \%$, there is an issue with tag migration and therefore, long-term tag visibility.
In conclusion, $A$. pallipes can be tagged with $8 \mathrm{~mm}$ PIT at a minimum CL of $22 \mathrm{~mm}$, without survival or growth being compromised., Care must be taken to ensure that the tag is injected into the muscle of the second or third segment of the ventral abdomen so that there is no risk of damaging internal organs during the insertion process. Although A. pallipes tagged with $8 \mathrm{~mm}$ PIT tags are detected at reduced distances to those with $12 \mathrm{~mm}$ PIT tags (mean difference $35.6 \mathrm{~mm}$ ) this drawback is outweighed by other benefits conveyed by using the smaller tag. An $8 \mathrm{~mm}$ tag allows captive born, sub-adult crayfish to be tagged, prior to release, and reduces the risk of internal organ damage to crayfish irrespective of size. Although PIT-tagging is more expensive than other internal marking methods, it currently offers the only $100 \%$ reliable method of permanently identifying individual animals and detecting them without having to recapture the individuals.

Acknowledgements. This work was funded by the Centre for Environment, Fisheries and Aquaculture Science, Mohamed bin Zayed Species Conservation Fund and Bristol Zoological Society. Thank you to Bristol Water for providing an aquaculture facility for the research. Thanks to Nathan Edmonds from the Centre of Environment, Fisheries and Aquaculture Science, Lowestoft, UK for assistance with this experiment.

\section{References}

Abrahamssons A. 1965. A method of marking crayfish Astacus astacus (Linneaus) in population studies. Oikos 16: 228-231.

Bates D, Maechler M, Bolker B, Walker S. 2015. Fitting linear mixedeffects models using Lme4. J. Stat Softw 67: 1-48.

Black T, Herleth-King S, Mattingly H. 2010. Efficacy of internal PIT tagging of small-bodied crayfish for ecological study, Southeastern Naturalist 9, (Special Publication 3), pp. 257-266.

Bubb D, Lucas M, Thom T, Rycroft P. 2002. The potential use of PIT telemetry for identifying and tracking crayfish in their natural environment. Hydrobiologia 483: 225-230.

Bubb D, Thom T, Lucas M. 2006. Movement patterns of the invasive signal crayfish determined by PIT telemetry. Can J Zool 84: 12021209.

Bubb D, Thom T, Lucas M. 2008. Spatial ecology of the white-clawed crayfish in an upland stream and implications for the conservation of this endangered species. Aquat Conserv 18: 647-657.

Burnett N, Stamplecoskie K, Thiem J, Cooke S. 2013. Comparison of detection efficiency among three sizes of half-duplex passive integrated transponders using manual tracking and fixed antenna arrays. N Am J Fish Manag 33: 7-13.

Burnham K, Anderson D, Huyvaert K. 2011. AIC model selection and multimodel inference in behavioural ecology: some background, observations, and comparisons. Behav Ecol Sociobiol 65: 23-35.

Buřič M, Kozák P, Vich P. 2008. Evaluation of different marking methods for spiny-cheek (Orconectes limosus). Knowl Manag Aquat Ecosyst 389: 2-8.

Cucheroussett J, Britton J, Beaumont W, Nyqvist M, Sievers K, Gozlan R. 2010. Determining the effects of species, environmental conditions and tracking method on the detection efficiency of portable PIT telemetry. J Fish Biol 76: 1039-1045.

Figiel C, Miller G. 1995. The frequency of chela autotomy and its influence on the growth and survival of the crayfish Procambarus clarkii (Girard 1852) (Decapoda Cambaridae). Crustaceana 68: 472-483. 
J. Nightingale et al.: Knowl. Manag. Aquat. Ecosyst. 2018, 419, 20

Füreder L, Gherardi F, Holdich D, Reynolds J, Sibley P, SoutyGrosset C. Austropotamobius pallipes. In: The IUCN Red List of Threatened Species 2010: e.T2430A9438817. Gland, Switzerland, and Cambridge, UK: International Union for Conservation of Nature, 2010, http://dx.doi.org/10.2305/IUCN.UK.2010-3.RLTS. T2430A9438817.en.

Gibbons J, Andrews K. 2004. PIT tagging: simple technology at its best. Bio Sci 54: 447-454.

Gotteland P. 2013. Test of injectable elastomer tags on white-clawed crayfish Austropotamobius pallipes (Lereboullet). Freshw Crayfish 19: 45-51.

Guan R. 1997. An improved method for marking crayfish. Crustaceana 70: 641-652.

Haddaway N, Mortimer R, Christmas M, Dunn A. 2010. A review of marking techniques for crustacea and experimental appraisal of electric Cauterisation and Visible Implant Elastomer Tagging for Austropotamobius pallipes and Pacifastacus leniusculus. Freshw Crayfish 9: 55-67.

Louca V, Ream H, Findlay J, Latham D, Lucas M. 2014. Do culverts impact the movements of the endangered white-clawed crayfish? Knowl Manag Aquat Ecosyst 414: 1-17.

Matthews M.A, Reynolds J.D. 1995 A population study of the whiteclawed crayfish Austropotamobius pallipes (Lereboullet) in an Irish reservoir. Biol Environ 95B: 99-109.

McMahan M, Cowan D, Sherwood G, Grabowski J, Chen Y. 2012. Evaluation of coded microwire tag retention in juvenile American lobster, Homarus americanus. J Crustac Biol 32: 497-502.

Morhardt J, Bishir D, Handlin C, Mulder S. 2000. A portable system for reading large passive integrated transponder tags from wild trout. N Am J Fish Manag 20: 276-283.

Nightingale J, Stebbing P, Sibley P, Brown O, Rushbrook B, Jones G. 2017. The use of ark sites and associated conservation measures to secure the long-term survival of white-clawed crayfish in the UK. Int Zoo Year J 53: 50-68.

Prentice E, Park D. 1983. A study to determine the biological feasibility of a new fish tagging system. Quarterly Progress Report, April-June 1983. Seattle: Coastal Zone and Estuarine Studies Division, Northwest Alaska Fisheries Centre National Marine Fisheries Service National Oceanic and Atmospheric Administration.

Ramalho R, McClain R, Anastácio P. 2010. An effective and simple method of temporarily marking crayfish. Freshw Crayfish 17: 5760.

Robinson C, Thom T, Lucas M. 2000. Ranging behaviour of a large freshwater invertebrate, the white-clawed crayfish Austropotamobius pallipes. Freshw Biol 44: 509-521.

Roussel J, Cunjak R, Newbury R, Caissie D, Haro A. 2004. Movements and habitat use by PIT-tagged Atlantic salmon parr in early winter: the influence of anchor ice. Freshw Biol 49: 10261035.

Shepherd T, Gardner C, Green B, Richardson A. 2011. Estimating survival of the tayatea Astacopsis gouldi (Crustacea, Decapoda, Parastacidae), an iconic, threatened freshwater invertebrate. $J$ Shellfish Res 30: 139-145.

Souty-Grosset C, Reynolds J. 2009. Current ideas on methodological approaches in European crayfish conservation and restocking procedures. Knowl Manag Aquat Ecosyst 401: 394-395.

Stead V, Cherrill A, Pope T. 2015. Tuning in to crayfish. Bull Chart Inst Ecol Environ Manag 89: 11-13.

Westhoff J, Sievert N. 2013. Mortality and growth of crayfish internally tagged with PIT tags. N Am J Fish Manag 33: 878-881.

Wiles P, Guan R. 1993. Studies on a new method for permanently tagging crayfish with microchip implants. Freshw Crayfish 9: 419425 .

Cite this article as: Nightingale J, Stebbing P, Taylor N, McCabe G, Jones G. 2018. The long-term effects and detection ranges of passive integrated transponders in white-clawed crayfish Austropotamobius pallipes. Knowl. Manag. Aquat. Ecosyst., 419, 20. 